\title{
IMPACT OF CLIMATE CHANGE ON GROUNDWATER RESOURCES
}

\author{
R. D. Singh \& C. P. Kumar \\ National Institute of Hydrology \\ Roorkee - 247667 (Uttarakhand)
}

\begin{abstract}
Climate change poses uncertainties to the supply and management of water resources. The Intergovernmental Panel on Climate Change (IPCC) estimates that the global mean surface temperature has increased $0.6 \pm 0.2{ }^{\circ} \mathrm{C}$ since 1861, and predicts an increase of 2 to $4{ }^{\circ} \mathrm{C}$ over the next 100 years. Temperature increases also affect the hydrologic cycle by directly increasing evaporation of available surface water and vegetation transpiration. Consequently, these changes can influence precipitation amounts, timings and intensity rates, and indirectly impact the flux and storage of water in surface and subsurface reservoirs (i.e., lakes, soil moisture, groundwater). In addition, there may be other associated impacts, such as sea water intrusion, water quality deterioration, potable water shortage, etc.

While climate change affects surface water resources directly through changes in the major long-term climate variables such as air temperature, precipitation, and evapotranspiration, the relationship between the changing climate variables and groundwater is more complicated and poorly understood. The greater variability in rainfall could mean more frequent and prolonged periods of high or low groundwater levels, and saline intrusion in coastal aquifers due to sea level rise and resource reduction. Groundwater resources are related to climate change through the direct interaction with surface water resources, such as lakes and rivers, and indirectly through the recharge process. The direct effect of climate change on groundwater resources depends upon the change in the volume and distribution of groundwater recharge. Therefore, quantifying the impact of climate change on groundwater resources requires not only reliable forecasting of changes in the major climatic variables, but also accurate estimation of groundwater recharge.

A number of Global Climate Models (GCM) are available for understanding climate and projecting climate change. There is a need to downscale GCM on a basin scale and couple them with relevant hydrological models considering all components of the hydrological cycle. Output of these coupled models such as quantification of the groundwater recharge will help in taking appropriate adaptation strategies due to the impact of climate change. This paper presents the status of research studies carried out at national and international level to quantify the impacts of climate change on groundwater resources and recommends direction for carrying out the R\&D studies to assess the impact of climate change on groundwater resources in the context of Indian conditions.
\end{abstract}

Keywords: Climate change; Hydrological cycle; Groundwater recharge; seawater intrusion; Numerical modeling; MODFLOW; UnSat Suite; WetSpass.

\section{Introduction}

Water is indispensable for life, but its availability at a sustainable quality and quantity is threatened by many factors, of which climate plays a leading role. The Intergovernmental Panel on Climate Change (IPCC) defines climate as "the average weather in terms of the mean and its variability over a certain time-span and a certain area" and a statistically significant variation of the mean state of the climate or of its variability lasting for decades or longer, is referred to as climate change.

Evidence is mounting that we are in a period of climate change brought about by increasing atmospheric concentrations of greenhouse gases. Atmospheric carbon dioxide levels have continually increased since the 1950s. The continuation of this phenomenon may significantly alter global and local climate characteristics, including temperature and precipitation. Climate change can have profound effects on the hydrologic cycle through precipitation, evapotranspiration, and soil moisture with increasing temperatures. The hydrologic cycle will be intensified with more evaporation and more precipitation. However, the extra precipitation will be unequally distributed around the globe. Some parts of the world may see significant reductions in precipitation or major alterations in the timing of wet and dry seasons. Information on the local or regional impacts of climate change on 
hydrological processes and water resources is becoming more important. The effects of global warming and climatic change require multi-disciplinary research, especially when considering hydrology and global water resources.

The Intergovernmental Panel on Climate Change (IPCC) estimates that the global mean surface temperature has increased $0.6 \pm 0.2{ }^{\circ} \mathrm{C}$ since 1861 , and predicts an increase of 2 to $4{ }^{\circ} \mathrm{C}$ over the next 100 years. Global sea levels have risen between 10 and $25 \mathrm{~cm}$ since the late 19th century. As a direct consequence of warmer temperatures, the hydrologic cycle will undergo significant impact with accompanying changes in the rates of precipitation and evaporation. Predictions include higher incidences of severe weather events, a higher likelihood of flooding, and more droughts. The impact would be particularly severe in the tropical areas, which mainly consist of developing countries, including India.

Coupled atmosphere-ocean global climate models (GCMs) are used to estimate changes in climate. These physically-based numerical models simulate synoptic-scale climate and hydrological processes, and are forced with greenhouse gas and aerosol emission scenarios. A wide diversity of GCMs developed by leading climate centres are available for other researchers to evaluate potential impacts of climate change. To ensure that the predictive elements from a GCM are realistic, a statistical downscaling technique should be employed to bridge the local- and synoptic-scale processes. Statistical downscaling uses a correlation between predictands (site measured variables, such as precipitation) and predictors (region-scale variables, such as GCM variables).

Changes in regional temperature and precipitation have important implications for all aspects of the hydrologic cycle. Variations in these parameters determine the amount of water that reaches the surface, evaporates or transpires back to the atmosphere, becomes stored as snow or ice, infiltrates into the groundwater system, runs off the land, and ultimately becomes base flow to streams and rivers.

Hydrological impact assessments of watersheds (and aquifers) require information on changes in evapotranspiration because it is a key component of the water balance. However, climate-change scenarios tend to be expressed in terms of changes in temperature and precipitation. Consequently, the effects of global warming on potential evaporation (or more inclusively, evapotranspiration) are not simple to estimate. Many global scenarios suggest an increase in potential evaporation, but these factors may be outweighed locally or regionally by other factors reducing evaporation. Various models may be used to calculate potential evaporation using data on net radiation, temperature, humidity, and wind speed, and sometimes plant physiological properties. The estimated effect of a change in climate on potential evaporation depends on the characteristics of the site.

Many rivers and streams that are fed by glacier runoff could be significantly impacted as a result of climate change. As glacier retreat accelerates, increased summer runoff could occur. However, when the glaciers have largely melted, the late summer and fall glacial input into streams and rivers may be lost, resulting in a significant reduction in flow in some cases.

Water resource management plans increasingly need to incorporate the affects of global climate change in order to accurately predict future supplies. Numerous studies have documented the sensitivity of streamflow to climatic changes for watersheds all over the world. Most of these studies involve watershed scale hydrologic models, of which validation remains a fundamental challenge. Moreover, outputs from general circulation models (GCM) can be rather uncertain and downscaling their predictions for local hydrologic use can produce inconsistent results. Therefore, the sensitivity of streamflow to climate changes is perhaps best understood by analyzing the historical records.

Building empirical models to link climate and regional hydrological regimes has a long history. In recent years, many researchers have used empirical rainfall-runoff model to study the impacts of climatic change on hydrology. However, applications of these empirical relationships to climate or basin conditions different from those used in the original development of these functions are questionable.

Although the most noticeable impacts of climate change could be fluctuations in surface water levels and quality, the greatest concern of water managers and government is the potential decrease and quality of groundwater supplies, as it is the main available potable water supply source for human consumption and irrigation of agriculture produce worldwide. Because groundwater aquifers are recharged mainly by precipitation or through interaction with 
surface water bodies, the direct influence of climate change on precipitation and surface water ultimately affects groundwater systems.

It is increasingly recognized that groundwater cannot be considered in isolation from the landscape above, the society with which it 'interacts', or from the regional hydrological cycle, but needs to be managed holistically. In understanding the likely consequences of possible future (climate and non-climate) changes on groundwater systems and the regional hydrological cycle, an important (but not exclusive) component to understand is the influence that these factors exert on recharge and runoff.

It is important to consider the potential impacts of climate change on groundwater systems. As part of the hydrologic cycle, it can be anticipated that groundwater systems will be affected by changes in recharge (which encompasses changes in precipitation and evapotranspiration), potentially by changes in the nature of the interactions between the groundwater and surface water systems, and changes in use related to irrigation.

Aside from the influence of climate, recharge to aquifers is very much dependent on the characteristics of the aquifer media and the properties of the overlying soils. Several approaches can be used to estimate recharge based on surface water, unsaturated zone and groundwater data. Among these approaches, numerical modelling is the only tool that can predict recharge. Modelling is also extremely useful for identifying the relative importance of different controls on recharge, provided that the model realistically accounts for all the processes involved. However, the accuracy of recharge estimates depends largely on the availability of high quality hydrogeologic and climatic data. Determining the potential impact of climate change on groundwater resources, in particular, is difficult due to the complexity of the recharge process, and the variation of recharge within and between different climatic zones.

When considering water resources in coastal zones, coastal aquifers are important sources of freshwater. However, salinity intrusion can be a major problem in these zones. Salinity intrusion refers to replacement of freshwater in coastal aquifers by saltwater. It leads to a reduction of available fresh groundwater resources. Changes in climatic variables can significantly alter groundwater recharge rates for major aquifer systems and thus affect the availability of fresh groundwater. Salinisation of coastal aquifers is a function of the reduction of groundwater recharge and results in a reduction of fresh groundwater resources.

A link between rising sea level and changes in the water balance is suggested by a general description of the hydraulics of groundwater discharge at the coast. Fresh groundwater rides up over denser, salt water in the aquifer on its way to the sea (Figure 1), and groundwater discharge is focused into a narrow zone that overlaps with the intertidal zone. The width of the zone of groundwater discharge measured perpendicular to the coast, is directly proportional to the discharge rate. The shape of the water table and the depth to the freshwater/saline interface are controlled by the difference in density between freshwater and salt water, the rate of freshwater discharge and the hydraulic properties of the aquifer. The elevation of the water table is controlled by mean sea level through hydrostatic equilibrium at the shore.

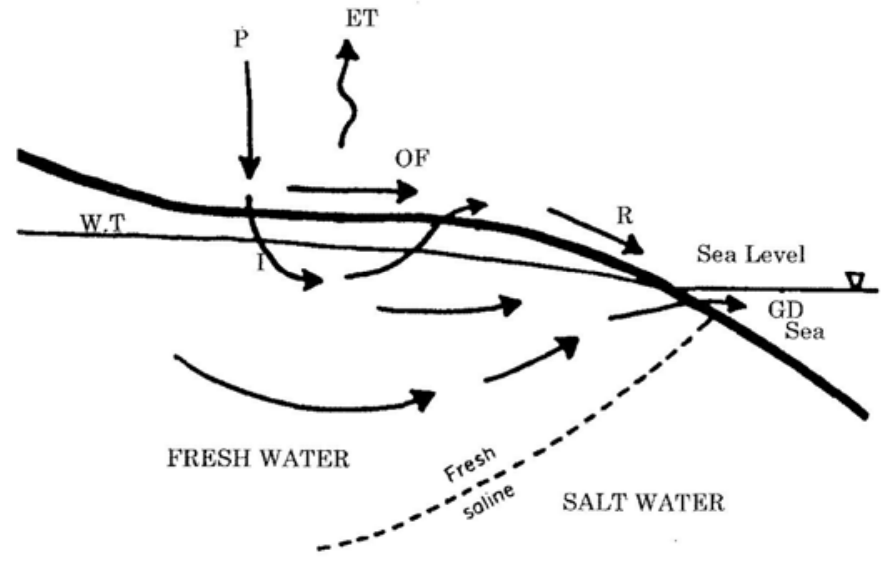

Figure 1: Conceptual Model of the Water Balance in a Coastal Watershed 
To assess the impacts of potential climate change on fresh groundwater resources, we should focus on changes in groundwater recharge and sea level rise on the loss of fresh groundwater resources in water resources stressed coastal aquifers.

\section{Climate Change Scenario for Groundwater in India}

Impact of climate change on the ground water regime is expected to be severe. It is to be pointed out that groundwater is the principle source of drinking water in the rural areas. About $85 \%$ of the rural water supply in India is dependent on groundwater. India on the whole has a potential of $45.22 \mathrm{Mha}-\mathrm{m} / \mathrm{year}$ of replenishable groundwater, Unfortunately, due to rampant drawing of the subsurface water, the water table in many regions of the country has dropped significantly in the recent years resulting in threat to groundwater sustainability. These regions mainly correspond to the states of Gujarat, Punjab, Haryana, Tamil Nadu and Rajasthan that have registered groundwater development above the national average. The situation in Gujarat, in particular, is critical. The water table in Ahmedabad is reported to be going down at the rate of 4 to 5 meters every year. In some localities of Delhi, the water table has fallen by over 10 meters. Even in Kerala, where the intensity of monsoon rain is heavy, water table has been falling systematically in all parts of the State.

The most optimistic assumption suggests that an average drop in groundwater level by one metre would increase India's total carbon emissions by over $1 \%$, because the time of withdrawal of the same amount of water will increase fuel consumption. A more realistic assumption reflecting the area projected to be irrigated by groundwater, suggests that the increase in carbon emission could be $4.8 \%$ for each metre drop in groundwater levels (Mall et al., 2006). It is recommended to study the aquifer geometry, establish the saline fresh interfaces within few $\mathrm{km}$ of the coastal area, the effect of glaciers melting on recharge potential of aquifers in the Ganga basin and its effects on the transboundary aquifer systems, particularly in the arid and semi-arid regions.

Climate change is likely to affect ground water due to changes in precipitation and evapotranspiration. Rising sea levels may lead to increased saline intrusion into coastal and island aquifers, while increased frequency and severity of floods may affect groundwater quality in alluvial aquifers. Sea-level rise leads to intrusion of saline water into the fresh groundwater in coastal aquifers and thus adversely affects groundwater resources. For two small and flat coral islands at the coast of India, the thickness of freshwater lens was computed to decrease from $25 \mathrm{~m}$ to $10 \mathrm{~m}$ and from $36 \mathrm{~m}$ to $28 \mathrm{~m}$, respectively, for a sea level rise of only $0.1 \mathrm{~m}$ (Mall et al., 2006).

Increased amount of precipitation in short heavy spells will lead to low infiltration thereby causing low moisture availability for soil. Furthermore, water management systems in the area like number of reservoirs, boreholes etc. would also modify the water availability. Global warming will also affect the water supply by changes in evaporation and ground water recharge. Finally through sea level rise, the global warming may contribute saline intrusion.

Agricultural demand, particularly for irrigation water, which is a major share of total water demand of the country, is considered more sensitive to climate change. A change in field-level climate may alter the need and timing of irrigation. Increased dryness may lead to increased demand, but demand could be reduced if soil moisture content rises at critical times of the year. It is projected that most irrigated areas in India would require more water around 2025 and global net irrigation requirements would increase relative to the situation without climate change by 3.5$5 \%$ by 2025 and $6-8 \%$ by 2075 . In India, roughly $52 \%$ of irrigation consumption across the country is extracted from groundwater; therefore, it can be an alarming situation with decline in groundwater and increase in irrigation requirements due to climate change.

Warm air holds more moisture and increase evaporation of surface moisture. With more moisture in the atmosphere, rainfall and snowfall events tend to be more intense, increasing the potential for floods. However, if there is little or no moisture in the soil to evaporate, the incident solar radiation goes into raising the temperature, which could contribute to longer and more severe droughts. Therefore, change in climate will affect the soil moisture, groundwater recharge and frequency of flood or drought episodes and finally groundwater level in different areas. In a number of studies, it is projected that increasing temperature and decline in rainfall may reduce net recharge and affect groundwater levels. However, little work has been done on hydrological impacts of possible climate change for Indian regions/basins. 
Existing economic growth scenarios project total power generation capacity in India to increase nine times from 96 GW to 912 GW between 1995-2100. As a result of climate change, it is estimated that approximately $1.5 \%$ more power generation capacity will be required. Increased energy demand may arise from a number of sources. For example, increases in average temperature can result in the need for space cooling for buildings, and variability in precipitation can impact irrigation needs and consequent demand for energy from groundwater pumping.

\section{Status of Research Studies}

The increase of concentration of carbon dioxide and other greenhouse gases in the atmosphere will certainly affect hydrological regimes. Global warning is thus expected to have major implications on water resources management. The observation of long-term trends in climate for many regions of the world has led to considerable research on the impact of greenhouse gases on climate. To this end, several general circulation models (GCMs) have been used to simulate the type of climate that might exist if global concentrations of carbon dioxide (greenhouse gas) were twice their pre-industrial levels. Recent GCM estimates of the projected rise in long-term global average annual surface temperature are between 1 and $4.5{ }^{\circ} \mathrm{C}$ under simulated doubled concentrations of $\mathrm{CO}_{2}$. On the subcontinent scale, there remains considerable uncertainty in the model results and it is not possible to know with confidence the fine details of how the climate will change regionally (Taylor 1997). Consequently, it is customary to use observational data as a baseline and adjust these by the GCM scenarios (Taylor 1997). Because precipitation patterns are significantly influenced by changes in the global-circulation patterns induced by climate change, regional projections for changes in precipitation under doubled $\mathrm{CO}_{2}$ scenarios remain very uncertain.

There have been many studies relating the effect of climate changes on surface water bodies. However, very little research exists on the potential effects of climate change on groundwater, although groundwater is the major source of drinking water across much of the world and plays a vital role in maintaining the ecological value of an area. Available studies show that groundwater recharge and discharge conditions are reflection of the precipitation regime, climatic variables, landscape characteristics and human impacts such as agricultural drainage and flow regulation. Hence, predicting the behavior of recharge and discharge conditions under future climatic and other changes is of great importance for integrated water management.

Studies which consider the indirect effects derived from climate-change-induced alterations in soil, land cover, saltwater intrusion due to rising sea levels and changes in water demand are less common. These studies represent a move away from impact studies (which may be considered to be vertically integrated, in which climate change acts upon an environmental compartment) towards horizontally integrated studies in which environmental compartments interact with each other. However, they remain an incomplete assessment of the pressures facing groundwater resources associated with the direct and indirect effects of future climate and socio-economic change.

Previous studies have typically coupled climate change scenarios with hydrological models, and have generally investigated the impact of climate change on water resources in different areas. The scientific understanding of an aquifer's response to climate change has been studied in several locations within the past decade. These studies link atmospheric models to unsaturated soil models, which, in some cases, were further linked into a groundwater model. The groundwater models used were calibrated to current groundwater conditions and stressed under different predicted climate change scenarios. Some of the recent studies on impact of climate change on groundwater resources have been discussed below.

Bouraoui et al. (1999) presented a general approach to evaluate the effect of potential climate changes on groundwater resources. In the current stage of knowledge, large-scale global climate models are probably the best available tools to provide estimates of the effects of raising greenhouse gases on rainfall and evaporation patterns through a continuous, three dimensional simulation of atmospheric, oceanic and cryospheric processes. However their spatial resolution (generally some thousands of square kilometers) is not compatible with that of watershed hydrologic models. The main purpose of this study is to evaluate the impact of potential climate changes upon groundwater resources. A general methodology is proposed in order to disaggregate outputs of large-scale models and thus to make information directly usable by hydrologic models. As an illustration, this method is applied to a $\mathrm{CO}_{2}$-doubling scenario through the development of a local weather generator, although many uncertainties are not yet assessed about the results of climate models. Two important hydrological variables: rainfall and potential evapotranspiration are thus generated. They are then used by coupling with a physically based hydrological model to estimate the effects of climate changes on groundwater recharge and soil moisture in the root zone. 
Sherif and Singh (1999) investigated the possible effect of climate change on sea water intrusion in coastal aquifers. There is increasing debate these days on climate change and its possible consequences. Much of the debate has focused in the context of surface water systems. In many arid areas of the world, rainfall is scarce and so is surface runoff. These areas rely heavily on groundwater. The consequences of climate change on groundwater are long term and can be far reaching. One of the more apparent consequences is the increased migration of salt water inland in coastal aquifers. Using two coastal aquifers, one in Egypt and the other in India, this study investigated the effect of likely climate change on sea water intrusion. Under conditions of climate change, the sea water levels will rise for several reasons, including variations in atmospheric pressures, expansion of warmer occasions and seas and melting of ice sheets and glaciers. The rise in sea water levels will impose additional saline water heads at the sea side and therefore more sea water intrusion is anticipated. Three realistic scenarios mimicking climate change were considered. Under these scenarios, the Nile Delta aquifer is found to be more vulnerable to climate change and sea level rise. A $50 \mathrm{~cm}$ rise in the Mediterranean sea level will cause additional intrusion of $9.0 \mathrm{~km}$ in the Nile Delta aquifer. The same rise in water level in the Bay of Bengal will cause an additional intrusion of $0.4 \mathrm{~km}$. Additional pumping will cause serious environmental effects in the case of the Nile Delta aquifer.

Ghosh Bobba (2002) analysed the effects of human activities and sea-level changes on the spatial and temporal behaviour of the coupled mechanism of salt-water and freshwater flow through the Godavari Delta of India. The density driven salt-water intrusion process was simulated with the use of a SUTRA (Saturated-Unsaturated TRAnsport) model. Physical parameters, initial heads, and boundary conditions of the delta were defined on the basis of available field data, and an areal, steady-state groundwater model was constructed to calibrate the observed head values corresponding to the initial development phase of the aquifer. Initial and boundary conditions determined from the areal calibration were used to evaluate steady-state, hydraulic heads. Consequently, the initial position of the hydraulic head distribution was calibrated under steady-state conditions. The changes of initial hydraulic distribution, under discharge and recharge conditions, were calculated, and the present-day position of the interface was predicted. The present-day distribution of hydraulic head was estimated via a 20 -year simulation. The results indicate that a considerable advance in seawater intrusion can be expected in the coastal aquifer if current rates of groundwater exploitation continue and an important part of the freshwater from the river is channelled from the reservoir for irrigation, industrial and domestic purposes.

Groundwater investigations are presently very active in Andhra Pradesh because of the urgent need for more water to meet the demands for the agricultural, industrial, and domestic purposes of the growing population in the coastal areas. This research has provided numerical simulation of the influence of surface flows, coming from the water management of the projected reservoir, on the regional groundwater behaviour in the delta aquifer. A twodimensional finite element model, considering open boundary conditions for coasts and a sharp interface between freshwater and salt water, was applied to the aquifer under steady-state conditions for freshwater surplus and deficits at the coastline. When recharges of salt water occur at the coastline, essentially of freshwater deficits, a hypothesis of mixing for the freshwater-salt water transition zone allows the model to calculate the resulting seawater intrusion in the aquifer. Hence, an adequate treatment and interpretation of the hydrogeological data, which are available for the coastal aquifer, were of main concern in satisfactorily applying the proposed numerical model. The results of the steady-state simulations showed reasonable calculations of the water table levels and the freshwater and salt-water thicknesses, as well as the extent of the interface and seawater intrusion into the aquifer for the total discharges or recharges in the delta and along the coastline.

As a result of the present hydrogeological conditions, a considerable advance in seawater intrusion would be expected in the coastal aquifer if current rates of groundwater exploitation continue and an important part of the freshwater from the river is channeled from the reservoir for irrigation, industrial and domestic purposes.

Allen et al. (2004) used the Grand Forks aquifer, located in south-central British Columbia, Canada as a case study area for modeling the sensitivity of an aquifer to changes in recharge and river stage consistent with projected climate-change scenarios for the region. Results suggested that variations in recharge to the aquifer under the different climate-change scenarios, modeled under steady-state conditions, have a much smaller impact on the groundwater system than changes in river-stage elevation of the Kettle and Granby Rivers, which flow through the valley. All simulations showed relatively small changes in the overall configuration of the water table and general direction of groundwater flow. High-recharge and low-recharge simulations resulted in approximately a $+0.05 \mathrm{~m}$ increase and a $-0.025 \mathrm{~m}$ decrease, respectively, in water table elevations throughout the aquifer. Simulated changes 
in river-stage elevation, to reflect higher-than-peak flow levels (by 20 and 50\%), resulted in average changes in the water-table elevation of 2.72 and $3.45 \mathrm{~m}$, respectively. Simulated changes in river-stage elevation, to reflect lowerthan-base flow levels (by 20 and 50\%), resulted in average changes in the water-table elevation of -0.48 and -2.10 $\mathrm{m}$, respectively. Current observed water table elevations in the valley are consistent with an average river-stage elevation (between current base flow and peak-flow stages).

Brouyere et al. (2004) developed an integrated hydrological model (MOHISE) in order to study the impact of climate change on the hydrological cycle in representative water basins in Belgium. This model considers most hydrological processes in a physically consistent way, more particularly groundwater flows which are modelled using a spatially distributed, finite-element approach. Thanks to this accurate numerical tool, after detailed calibration and validation, quantitative interpretations can be drawn from the groundwater model results. Considering IPCC climate change scenarios, the integrated approach was applied to evaluate the impact of climate change on the water cycle in the Geer basin in Belgium. The groundwater model is described in detail and results are discussed in terms of climate change impact on the evolution of groundwater levels and groundwater reserves. From the modelling application on the Geer basin, it appears that, on a pluri-annual basis, most tested scenarios predict a decrease in groundwater levels and reserves in relation to variations in climatic conditions. However, for this aquifer, the tested scenarios show no enhancement of the seasonal changes in groundwater levels.

Holman (2006) described an integrated approach to assess the regional impacts of climate and socio-economic change on groundwater recharge from East Anglia, UK. Many factors affect future groundwater recharge including changed precipitation and temperature regimes, coastal flooding, urbanization, woodland establishment, and changes in cropping and rotations. Important sources of uncertainty and shortcomings in recharge estimation were discussed in the light of the results. The uncertainty in, and importance of, socio-economic scenarios in exploring the consequences of unknown future changes were highlighted. Changes to soil properties are occurring over a range of time scales, such that the soils of the future may not have the same infiltration properties as existing soils. The potential implications involved in assuming unchanging soil properties were described.

Mall et al. (2006) examined the potential for sustainable development of surface water and groundwater resources within the constraints imposed by climate change and future research needs in India.In recent times, several studies around the globe show that climatic change is likely to impact significantly upon freshwater resources availability. In India, demand for water has already increased manifold over the years due to urbanization, agriculture expansion, increasing population, rapid industrialization and economic development. At present, changes in cropping pattern and land-use pattern, over-exploitation of water storage and changes in irrigation and drainage are modifying the hydrological cycle in many climate regions and river basins of India. An assessment of the availability of water resources in the context of future national requirements and expected impacts of climate change and its variability is critical for relevant national and regional long-term development strategies and sustainable development.

He concluded that the Indian region is highly sensitive to climate change. The elements/sectors currently at risk are likely to be highly vulnerable to climate change and variability. It is urgently required to intensify in-depth research work with the following objectives:

- Analyse recent experiences in climate variability and extreme events, and their impacts on regional water resources and groundwater availability.

- Study on changing patterns of rainfall, i.e. spatial and temporal variation and its impact on run-off and aquifer recharge pattern.

- Study sea-level rise due to increased run-off as projected due to glacial recession and increased rainfall.

- Sea-water intrusions into costal aquifers.

- Determine vulnerability of regional water resources to climate change and identify key risks and prioritize adaptation responses.

- Evaluate the efficacy of various adaptation strategies or coping mechanisms that may reduce vulnerability of the regional water resources.

It has been the endeavour of this study to summarize some important vulnerability issues associated with the present and potential future hydrological responses due to climate change and highlight those areas where further research is required. The National Environment Policy (2004) also advocated that anthropogenic climate changes have severe 
adverse impacts on India's precipitation patterns, ecosystems, agricultural potential, forests, water resources, coastal and marine resources. Large-scale planning would be clearly required for adaptation measures for climate change impacts, if catastrophic human misery is to be avoided.

Ranjan et al. (2006) evaluated the impacts of climate change on fresh groundwater resources specifically salinity intrusion in water resources stressed coastal aquifers. Their assessment used the Hadley Centre climate model, HadCM3 with high and low emission scenarios (SRES A2 and B2) for years 2000-2099. In both scenarios, the annual fresh groundwater resources losses indicated an increasing long-term trend in all stressed areas, except in the northern Africa/Sahara region. They also found that precipitation and temperature individually did not show good correlations with fresh groundwater loss. However, the relationship between the aridity index and fresh groundwater loss exhibited a strong negative correlation. They also discussed the impacts of loss of fresh groundwater resources on socio-economic activities, mainly population growth and per capita fresh groundwater resources.

Scibek and Allen (2006) developed a methodology for linking climate models and groundwater models to investigate future impacts of climate change on groundwater resources. An unconfined aquifer, situated near Grand Forks in south central British Columbia, Canada, was used to test the methodology. Climate change scenarios from the Canadian Global Coupled Model 1 (CGCM1) model runs were downscaled to local conditions using Statistical Downscaling Model (SDSM), and the change factors were extracted and applied in LARS-WG stochastic weather generator and then input to the recharge model. The recharge model simulated the direct recharge to the aquifer from infiltration of precipitation and consisted of spatially distributed recharge zones, represented in the Hydrologic Evaluation of Landfill Performance (HELP) hydrologic model linked to a geographic information system (GIS). A three-dimensional transient groundwater flow model, implemented in MODFLOW, was then used to simulate four climate scenarios in 1-year runs (1961-1999 present, 2010-2039, 2040-2069, and 2070-2099) and compare groundwater levels to present. The effect of spatial distribution of recharge on groundwater levels, compared to that of a single uniform recharge zone, is much larger than that of temporal variation in recharge, compared to a mean annual recharge representation. The predicted future climate for the Grand Forks area from the downscaled CGCM1 model will result in more recharge to the unconfined aquifer from spring to the summer season. However, the overall effect of recharge on the water balance is small because of dominant river-aquifer interactions and river water recharge.

Woldeamlak et al. (2007) modeled the effects of climate change on the groundwater systems in the Grote-Nete catchment, Belgium, covering an area of $525 \mathrm{~km}_{2}$, using wet (greenhouse), cold or NATCC (North Atlantic Thermohaline Circulation Change) and dry climate scenarios. Low, central and high estimates of temperature changes were adopted for wet scenarios. Seasonal and annual water balance components including groundwater recharge were simulated using the WetSpass model, while mean annual groundwater elevations and discharge were simulated with a steady-state MODFLOW groundwater model. WetSpass results for the wet scenarios showed that wet winters and drier summers are expected relative to the present situation. MODFLOW results for wet high scenario showed groundwater levels increase by as much as $79 \mathrm{~cm}$, which could affect the distribution and species richness of meadows. Results obtained for cold scenarios depict drier winters and wetter summers relative to the present. The dry scenarios predict dry conditions for the whole year. There is no recharge during the summer, which is mainly attributed to high evapotranspiration rates by forests and low precipitation. Average annual groundwater levels drop by $0.5 \mathrm{~m}$, with maximum of $3.1 \mathrm{~m}$ on the eastern part of the Campine Plateau. This could endanger aquatic ecosystem, shrubs, and crop production.

Hsu et al. (2007) adopted a numerical modeling approach to investigate the response of the groundwater system to climate variability to effectively manage the groundwater resources of the Pingtung Plain. The Pingtung Plain is one of the most important groundwater-resource areas in southwestern Taiwan. The overexploitation of groundwater in the last two decades has led to serious deterioration in the quantity and quality of groundwater resources in this area. Furthermore, the manifestation of climate change tends to induce the instability of surface-water resources and strengthen the importance of the groundwater resources. Southwestern Taiwan in particular shows decreasing tendencies in both the annual amount of precipitation and annual precipitation days. A hydrogeological model was constructed based on the information from geology, hydrogeology, and geochemistry. Applying the linear regression model of precipitation to the next two decades, the modeling result shows that the lowering water level in the proximal fan raises an alarm regarding the decrease of available groundwater in the stress of climate change, and the enlargement of the low-groundwater-level area on the coast signals the deterioration of water quantity and quality in 
the future. Suitable strategies for water-resource management in response to hydrological impacts of future climatic change are imperative.

Fu et al. (2007) developed and implemented a methodology to estimate the impacts of global climate change on regional hydrological regimes using ArcGIS Geostatistical Analyst. The model is easily used and can be expanded to different watersheds. The ArcGIS Geostatistical Analyst interface provides a comprehensive set of tools for creating surfaces from measured sample points compared with the previous method of using adjustable tension continuous curvature surface gridding. As a result, users can rapidly compare different interpolation techniques in order to obtain the best solution. Model results can subsequently be used in GIS models for visualization and analyses. The methodology was applied to the Spokane River Watershed. Results indicate that a $30 \%$ precipitation increase causes a $50 \%$ increase of streamflow when the temperature is normal compared to only a $20-30 \%$ increase in streamflow if the average annual air temperature is $1.5^{\circ} \mathrm{C}$ higher than normal. Conversely, a $20 \%$ precipitation decrease results in approximately $25-30 \%$ less streamflow when the temperature is normal but a $45 \%$ decrease in streamflow if the temperature is $1.5^{\circ} \mathrm{C}$ higher than normal. These research results can be used as reference conditions for long-term watershed water management strategies under global warming scenarios. The precipitation elasticity of runoff is also investigated. The precipitation elasticity was found to be 1.67 although it varied with precipitation and temperature.

An analysis of streamflow response to global climate change was completed for the Spokane River Watershed. The modified method can easily and quickly provide results based on observed historical data with the help of ArcGIS Geostatistical Analyst. The methodology is easily used and expanded to different watersheds. Users can compare different model results and use the best interpolation techniques for the specific watershed of interest.

Toews (2007) modeled the impacts of future predicted climate change on groundwater recharge resources for the arid to semi-arid south Okanagan region, British Columbia. The hydrostratigraphy of the region consists of Pleistocene-aged glaciolacustrine silt overlain by glaciofluvial sand and gravel. Spatial recharge was modelled using available soil and climate data with the HELP 3.80D hydrology model. Climate change effects on recharge were investigated using stochastically-generated climate from three GCMs. Recharge is estimated to be $\sim 45 \mathrm{~mm} /$ year, with minor increases expected with climate change. However, growing season and crop water demands will increase, posing additional stresses on water use in the region. A transient MODFLOW groundwater model simulates increases of water table in future time periods, which is largely driven by irrigation application increases. Spatial recharge was also used in a groundwater model to define capture zones around eight municipal water wells. These capture zones will be used for community planning.

These studies are still at infancy and more data, in terms of field information are to be generated. This will also facilitate appropriate validation of the simulation for the present scenarios. However, it is clear that the global warming threat is real and the consequences of climate change phenomena are many and alarming.

\section{Methodology to Assess the Impact of Climate Change on Groundwater Resources}

The potential impacts of climate change on water resources have long been recognized although there has been comparatively little research relating to groundwater. The principle focus of climate change research with regard to groundwater has been on quantifying the likely direct impacts of changing precipitation and temperature patterns. Such studies have used a range of modelling techniques such as soil water balance models, empirical models, conceptual models and more complex distributed models, but all have derived changes in groundwater recharge assuming parameters other than precipitation and temperature remaining constant.

There are two main parameters that could have a significant impact on groundwater levels: recharge and river stage/discharge. To assess the impact on the groundwater system to changes in these two parameters, it is necessary to have a calibrated flow model

and to conduct a sensitivity analysis by varying these two parameters and calculating changes to the water balance (e.g., differences in water levels). The research objectives can be:

To develop a conceptual model of the hydrogeology of the study region;

> To investigate how regional and local weather events affect recharge; 
$>$ To determine potential impacts of climate change on recharge for the study area, and to assess the sensitivity of the results to different global climate models;

$>$ To develop and calibrate a regional-scale three-dimensional groundwater flow model of the region and to use that model to assess the impacts of climate change on groundwater resources; and

> To develop and calibrate a local-scale three-dimensional groundwater flow model, and to undertake a well capture zone analysis for the local community water supply wells for the region.

The methodology consists of three main steps. To begin with, climate scenarios can be formulated for the future years such as 2050 and 2100. This is done by assigning percentage or value changes of climatic variables on a seasonal and/or annual basis only for the future years relative to the present year. Secondly, based on these scenarios and present situation, seasonal and annual recharge, evapotranspiration and runoff are simulated with the WHI UnSat Suite (HELP module for recharge) and/or WetSpass model. Finally, the annual recharge outputs from WHI UnSat Suite or WetSpass model are used to simulate groundwater system conditions using steady-state MODFLOW model setups for the present condition and for the future years.

The main tasks that are involved in such a study are:

1. Describe hydrogeology of the study area.

2. Undertake a statistical analysis to separate climate into regional and local events and determine the role of each in contributing to groundwater recharge.

3. Analyze climate data from weather stations and modelled GCM, and build future predicted climate change datasets with temperature, precipitation and solar radiation variables.

4. Define methodology for estimating changes to recharge in the model under both current climate conditions and for the range of climate-change scenarios for the study area.

5. Use of a computer code (such as WHI UnSat Suite or WetSpass) to estimate recharge based on available precipitation and temperature records and anticipated changes to these parameters.

\section{Recharge estimation by WHI UnSat Suite}

UnSat Suite contains the subprogram, Visual HELP, which contains a more user-friendly interface for the program HELP that is approved by the United States Environmental Protection Agency (US EPA) for designing landfills. Visual HELP enables the modeler to generate estimates of recharge using a weather generator and the properties of the aquifer column.

\section{Recharge estimation by WetSpass}

WetSpass is a quasi physically distributed seasonal-water balance model, which takes into account detailed soil, land-use, slope, groundwater depth, and hydro-climatological distributed maps with associated parameter tables for estimating groundwater recharge. The model uses seasonal (summer and winter) geographical information systems (GIS) input grids of the mentioned inputs to estimate annual and seasonal groundwater recharge values.

6. Quantify the spatially distributed recharge rates using the climate data and spatial soil survey data.

7. Development and calibration of a three-dimensional regional-scale groundwater flow model (such as Visual MODFLOW). Since one of the inputs required for WetSpass is the groundwater depth data, which is predicted with the MODFLOW model, an interface may be developed in an ArcView GIS platform to couple the two models, facilitating exchange of data between the two models. The coupled WetSpass- 
MODFLOW model is run for the present situation and for each of the climate change scenarios on an annual basis.

8. Simulate groundwater flow using each recharge data set and evaluate the changes in groundwater flow and levels through time.

9. Undertake sensitivity analysis of the groundwater flow model.

10. Develop a local scale groundwater model for the specific study area and conduct a well capture zone analysis.

A typical flow chart for various aspects of such a study is shown in Figure 2. The figure shows the connection from the climate analysis, to recharge simulation, and finally to a groundwater model. Recharge is applied to a threedimensional groundwater flow model, which is calibrated to historical water levels. Transient simulations are undertaken to investigate the temporal response of the aquifer system to historic and future climate periods.

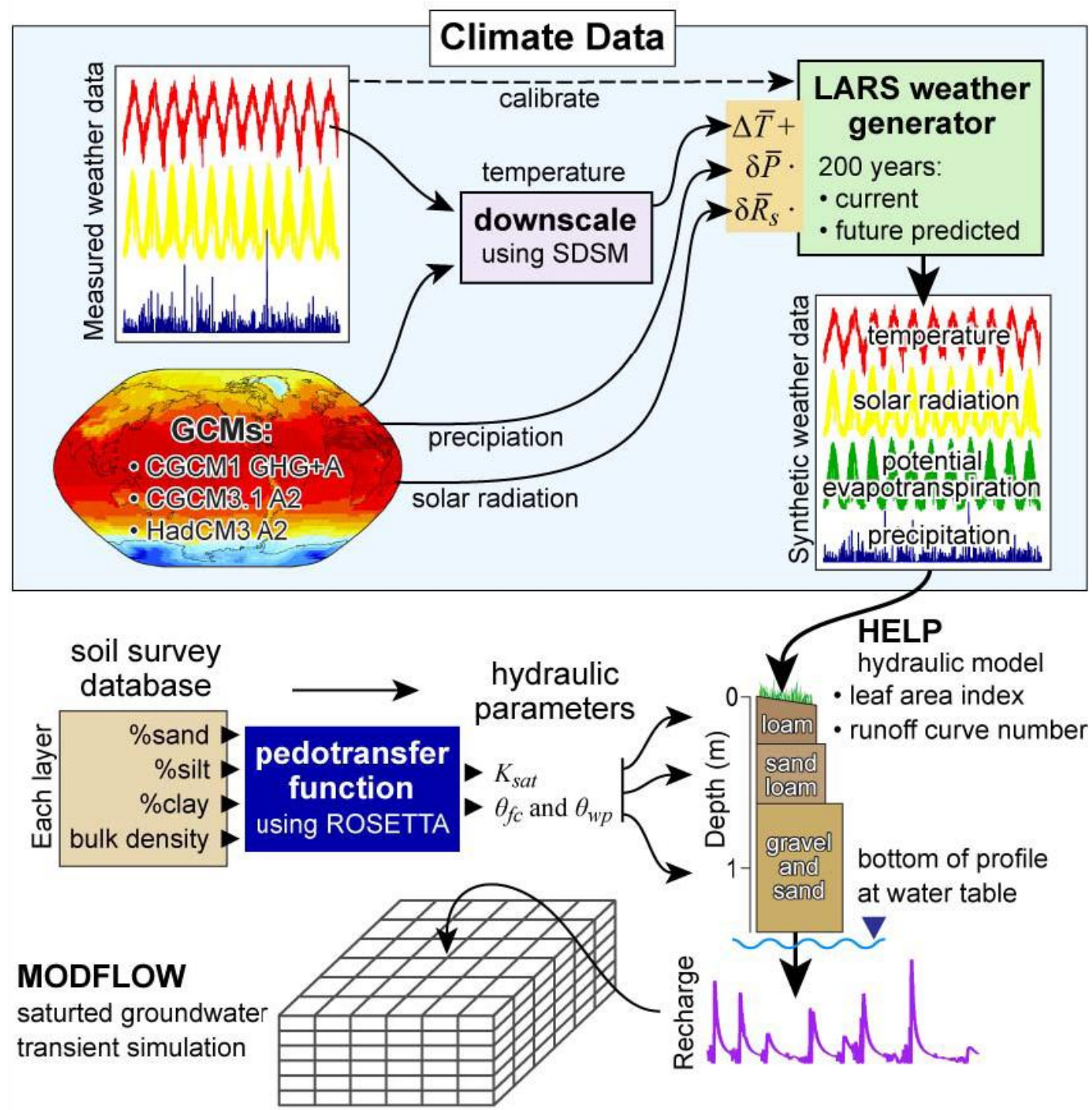

Figure 2: Flow Chart of Tasks (Toews et al., 2007) 
Tasks in the upper part of the chart assemble several climate data sets for current and future predicted conditions, which are used to simulate recharge using HELP module of WHI UnSat Suite. The soil layers are parameterized using a pedotransfer function program, which utilizes detailed soil survey measurements. Mapped monthly recharge from HELP is then used in a three-dimensional MODFLOW model to simulate transient saturated groundwater flow.

\section{Concluding Remarks}

> Precipitation is commonly downscaled in climate change impact studies; however, the reliability of the downscaled result is often poor or unreliable, as there is often little correlation between the predictors and the predictands. A poor correlation is often attributed to mesoscale processes occurring at the site-scale that are not represented in regional models due to their representative spatial and temporal sizes in comparison to larger-scale regional precipitation. Mesoscale precipitation processes generally occur in the summer season in the form of convective clouds, which are a result of local-scale evapotranspiration from elevated temperatures and solar radiation magnitudes. As a result, global-scale models may underestimate the summer precipitation measured at a site.

> Although climate change has been widely recognized, research on the impacts of climate change on the groundwater system is relatively limited. The reasons may be that long historical data are required to analyze the characteristics of climate change. These data are not always available. Also, the driving forces that cause such changes are yet unclear. The climatic abnormality may occur frequently and last for a period of time. Even if the required data exist, uncertainty is embedded in model parameters, structure and driving force of the hydrological cycle. Predicting the long-term effect of a dynamic system is very difficult because of limitations inherent in the models, and the unpredictability of the forces that drive the earth. A physically based model of a groundwater system under possible climate change based on available data is very important to prevent the deterioration of regional water-resource problems in the future. Although uncertainties are inevitable, new response strategies in water resource management based on the model may be useful.

$>$ The investigation of the relationship between climate change and loss of fresh groundwater resources is important for understanding the characteristics of the different regions. The impact of future climatic change may be felt more severely in developing countries such as India, whose economy is largely dependent on agriculture and is already under stress due to current population increase and associated demands for energy, freshwater and food. In spite of the uncertainties about the precise magnitude of climate change and its possible impacts, particularly on regional scales, measures must be taken to anticipate, prevent or minimize the causes of climate change and mitigate its adverse effects.

$>$ If the likely consequences of future changes of groundwater recharge, resulting from both climate and socio-economic change, are to be assessed, hydrogeologists must increasingly work with researchers from other disciplines, such as socio-economists, agricultural modelers and soil scientists.

\section{References}

Allen, D. M., Mackie, D. C., Wei, M. (2004), Groundwater and climate change: a sensitivity analysis for the Grand Forks aquifer, southern British Columbia, Canada, Hydrogeology Journal, Vol. 12, pp. 270-290.

Bouraoui, F., Vachaud, G., Li, L. Z. X., Le Treut, H,, Chen, T. (1999), Evaluation of the impact of climate changes on water storage and groundwater recharge at the watershed scale, Climate Dynamics, Vol. 15, pp. 153-161.

Brouyere, S., Carabin, G., Dassargues, A. (2004), Climate change impacts on groundwater resources: modelled deficits in a chalky aquifer, Geer basin, Belgium, Hydrogeology Journal, Vol. 12, pp. 123-134.

CGWB (2002), Master Plan for Artificial Recharge to Groundwater in India, Central Ground Water Board, New Delhi, February 2002, p. 115. 
Chadha, D. K. and Sharma, S. K. (2000), Groundwater management in India issues and options, Workshop on Past Achievements and Future Strategies, Central Groundwater Authority, New Delhi, 14 January 2000.

Climate Change \& its Impact on Indian Water Resources: Assessment, Adaptation \& Mitigation, Base Paper by National Institute of Hydrology, Roorkee.

Das, P. K. and Radhakrishnan, M. (1991), Proc. Indian Acad. Sci. (Earth Planet. Sci.), Vol. 100, pp. 177-194.

Fu, Guobin, Barber, Michael E., Chen, Shulin (2007), Impacts of Climate Change on Regional Hydrological Regimes in the Spokane River Watershed, Journal Of Hydrologic Engineering, September/October 2007, pp. 452461.

Ghosh Bobba, A. (2002), Numerical modelling of salt-water intrusion due to human activities and sea-level change in the Godavari Delta, India, Hydrological Sciences Journal, Vol. 47(S), August 2002, pp. 67-80.

Holman, I. P. (2006), Climate change impacts on groundwater recharge - uncertainty, shortcomings, and the way forward?, Hydrogeology Journal, Vol. 14, pp. 637-647.

Hsu, Kuo-Chin, Wang, Chung-Ho, Cheu, Kuan-Chih, Chen, Chien-Tai, Ma, Kai-Wei (2007), Climate-induced hydrological impacts on the groundwater system of the Pingtung Plain, Taiwan, Vol. 15, Number 5, August 2007, pp. 903-913.

IPCC (1995), Report of Working Group I of the Intergovernmental Panel on Climate Change, World Meteorological Organization, United Nations Environment Program, Geneva.

IPCC (1997), The regional impact of climate change: an assessment of vulnerability: A Special Report of IPCC working group II, Watson, R. T., Zinyowera, M. C., Moss, R. H., Dokken, D. J. (Eds), http://www.grida.no/climate/ipcc/regional/index.htm, Cited 19 November 2006.

IPCC (2000), Emissions Scenarios: A Special Report of Working Group II of the Intergovernmental Panel on Climate Change, In: Nakicenovic, N., Swart, R. (Eds.), Cambridge Univ. Press, Cambridge, UK.

IPCC (2001), In: Houghton, J. T., Ding, Y., Griggs, D. J., Noguer, M., van der Linden, P. J., Dai, X., Maskell, K., Johnson, C.A. (Eds.), Climate Change 2001: The Scientific Basis, Contributions of Working Group 1 to the Third Assessment Report of the Intergovernmental Panel on Climate Change, Cambridge University Press, Cambridge, UK.

IPCC (2007), In: Solomon, S., Qin, D., Manning, M., Chen, Z., Marquis, M., Averyt, K. B., Tignor, M., Miller, H. L. (eds.), 2007. Climate Change 2007: The Physical Science Basis. Contribution of Working Group I to the Fourth Assessment Report of the Intergovernmental Panel on Climate Change, Cambridge University Press, Cambridge, UK and New York, NY, USA, 966 p.

Mall, R. K., Gupta, Akhilesh, Singh, Ranjeet, Singh, R. S., Rathore, L. S. (2006), Water resources and climate change: An Indian perspective, Current Science, Vol. 90, No. 12, 25 June 2006.

National Environment Policy (2004), Ministry of Environment and Forests, Government of India, p. 38.

Ranjan, P., Kazamaa, S., Sawamoto, M. (2006), Effects of climate change on coastal fresh groundwater resources, Global Environmental Change, Vol. 16, pp. 388-399.

Ravindranath, N. H., Joshi, N. V., Sukumar, R., Saxena, A. (2005), Impact of climate change on forests in India, Current Science, Vol. 90, pp. 354-361.

Rupa Kumar, K. (2005), High-resolution climate change scenarios for India for the 21st century, Current Science, Vol. 90, pp. 334-345. 
Sathaye, Jayant, Shukla, P. R., Ravindranath, N. H. (2006), Climate change, sustainable development and India: Global and national concerns, Current Science, Vol. 90, Number 3, 10 February 2006, pp. 314-325.

Scibek, J., Allen, D. M. (2006), Modeled impacts of predicted climate change on recharge and groundwater levels, Water Resources Research, Vol. 42, W11405, 18p.

Sherif, Mohsen M., Singh, Vijay P. (1999), Effect of climate change on sea water intrusion in coastal aquifers, Hydrological Processes, Vol. 13, pp. 1277-1287.

Taylor B. (1997), Climate change scenarios for British Columbia and Yukon, In: Taylor E, Taylor B. (eds), Responding to global climate change in British Columbia and Yukon, Volume I of the Canada country study: climate impacts and adaptation, Environment Canada and BC Ministry of Environment, Lands and Parks.

Toews, Michael W. (2007), Modelling Climate Change Impacts on Groundwater Recharge an a Semi-Arid Region, Southern Okanagan, British Columbia, A thesis submitted in partial fulfillment of the requirements for the degree of Master of Science in the Department of Earth Sciences, Simon Fraser University.

UNFCCC (2004), India's Initial National Communications to the United Nations Framework Convention on Climate Change, Ministry of Environment and Forests, New Delhi.

Woldeamlak, S. T., Batelaan, O., De Smedt, F. (2007), Effects of climate change on the groundwater system in the Grote-Nete catchment, Belgium, Hydrogeology Journal, Vol. 15, Number 5, August 2007, pp. 891-901. 